\title{
Machinability of titanium alloys (Ti6Al4V and Ti555.3)
}

\author{
P.-J. Arrazola ${ }^{a, *}$, A. Garay ${ }^{a}$, L.-M. Iriarte ${ }^{a}$, M. Armendia ${ }^{a}$, \\ S. Marya ${ }^{b}$, F. Le Maître ${ }^{c}$ \\ a E.P.S. de Mondragon Unibertsitatea, Mondragón, Spain \\ b L.M.M. of Ecole Centrale de Nantes, Nantes, France \\ c Association Française du Titane, Nantes, France
}

\begin{abstract}
Near-beta titanium alloys like Ti555.3 are increasingly being used in aeronautics replacing in some critical applications the most common Ti6Al4V. However, these near-beta titanium alloys have a poor machinability rating which needs to be overcome so as to maintain at least the same productivity levels as in Ti6Al4V.

This paper presents the machinability results carried out for Ti555.3 compared with the commonly used Ti6Al4V. The aim of this research work is to understand tool wear mechanisms when machining Ti555.3. Analysis of variables such as cutting forces, chip geometry and tool wear shows that: (I) greater difficulty is encounterd when machining Ti555.3 alloy compared with Ti6Al4V alloy which can be machined at higher speeds up to $90 \mathrm{~m} \mathrm{~min}^{-1}$; (II) there was a correlation between the mechanical properties of work material, tool wear, and component forces; (III) the occurrence of the diffusion process leads to the formation of a layer of adhered material composed of Ti and TiC on the tool's rake face for both Ti alloys.
\end{abstract}

* Corresponding author. Tel.: +34 9437396 64; fax: +34 943791536.

E-mail address: pjarrazola@eps.mondragon.edu (P.-J. Arrazola). 0924-0136/\$ - see front matter @ 2008 Elsevier B.V. All rights reserved. doi:10.1016/j.jmatprotec.2008.06.020 


\section{Introduction}

Titanium alloys have received considerable interest recently due to their wide range of applications in the aerospace, automotive, chemical, and medical industries.

The most common titanium alloy is Ti6Al4V, which belongs to the $\alpha+\beta$ alloy group and accounts for more than $50 \%$ of the titanium alloy production. However, in order to achieve weight savings, new alloys are being developed. Boyer and Briggs (2004) analyzed the properties and different applications of the new beta titanium alloys, which are being used by aerospace companies because they provide an exceptional combination of fracture toughness, high strength, simpler processing, and deep hardenability. One of the latest developed alloys is the Ti555.3, which can be heat treated to high strengths, with minimum tensile strength values of above $1200 \mathrm{MPa}$. This high tensile strength makes Ti555.3 a promising material for advanced structural and landing gear applications, compared with traditional titanium alloys such as Ti6Al4V.

Fanning (2005) has already analyzed the properties of this alloy and its applications in aircrafts. However, there are no publications regarding the machinability of Ti555.3. In this paper, a study of the machinability of this new alloy compared with the most common titanium alloy Ti6Al4V is carried out, presenting, for the first time, experimental data for tool life in turning operations.

First, a microstructural and compositional study is presented, followed by an experimental plan and setup. The results are then discussed, and finally, the overall conclusions are highlighted.

\section{Presentation of the titanium alloys}

The titanium alloy, Ti555.3, has a metastable beta structure and belongs to the family of near-beta alloys. This distinct behaviour is due to the presence of beta stabilizers such as Mo, V, Fe, Cr, etc. Fig. 1 shows the phase diagram for Ti alloys.

The microstructures of the Ti6Al4V and Ti555.3 alloys are significantly different with respect to the quantities and mor-

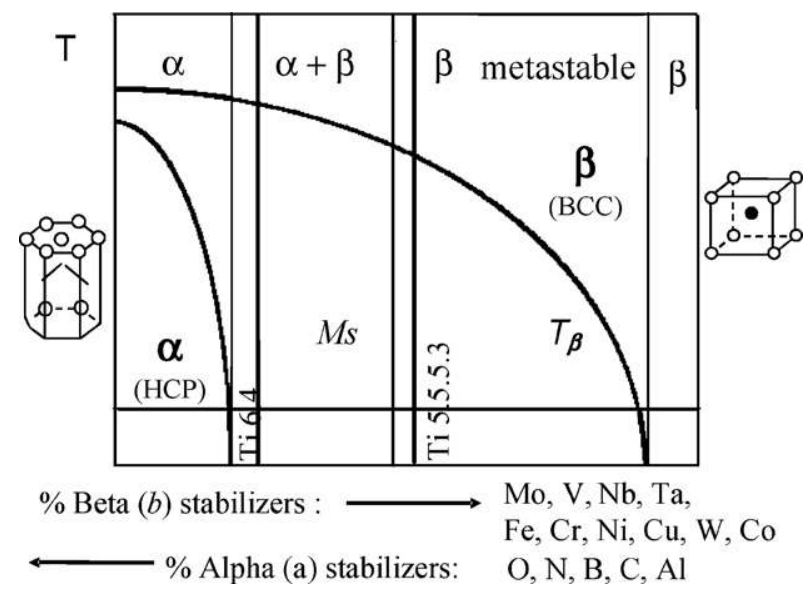

Fig. 1 - Phase diagram of the titanium alloys (E. Gautier and B. Appolaire, Ecole de Mines de Nancy, France). phologies of the primary alpha and the transformed beta phases as well as the grain size.

There is a major quantity (80\%) of the primary or residual alpha phase in Ti6Al4V, (Fig. 2a), while the Ti555.3 alloy has $20 \%$ of the globular residual alpha phase along with the beta-alpha Widmanstätten-transformed phase (Fig. 2b).

The knowledge of the transus temperature (Table 1) along with the thermal history of the respective treatments allows the generation of predictive information for each alloy: the quantity of residual alpha phase and the amount of beta phase transformed in both the alpha-grain boundary (alpha-GB) and alpha-Widmanstätten grain boundary (WGB).

Titanium alloys can be classified based on the value of the $\mathrm{Al}$ and Mo equivalent parameters (see Table 1). The $\mathrm{Al}$ equivalent value indicates the capacity of the alloy to obtain a given hardness, whereas the Mo equivalent value indicates the capacity to obtain an ultimate tensile strength (UTS) and hardness in the aged condition. The near-beta alloy (Ti555.3) has a Mo-equivalent value of nearly 8 times higher than that of the Ti6Al4V alloy (Table 1). This observation explains the higher mechanical properties of these near-beta titanium alloys compared with the traditional Ti6Al4V alloys.

Higher difficulties are expected when machining Ti555.3 compared with the Ti6Al4V alloy because of the following factors: (I) the mechanical properties, especially the hardness and the tensile stress at high temperatures $\left(400^{\circ} \mathrm{C}\right)$, (II) the differences of structure with a variable quantity of the alpha phase, and (III) the morphology of the transformed beta phase.

\section{Experimental plan and set up}

Experiments were carried out on a computerized numerical control (CNC) lathe (Fig. 3). The diameters of the Ti alloy bars used varied from 150 to $400 \mathrm{~mm}$. To eliminate the material heterogeneities produced in the forged upset specimens, material thickness varying from 10 to $20 \mathrm{~mm}$ was machined off the external diameter. The Ti6Al4V alloy was quenched and annealed and the Ti555.3 alloy was solution-treated and aged before the machining trials.

Different methods can be used to analyze the results of the cutting tests: tool life versus cutting speed, tool wear versus cutting time, or tool wear versus cutting speed. The last approach has been used in this study to determine the maximum cutting speed $\left(v_{\mathrm{cmax}}\right)$ that can be used for each alloy, i.e., the cutting speed at which rapid tool wear occurs.

Kahles et al. (1985) observed that when machining titanium alloys, the tool life is very sensitive to the changes in feed $(f)$. Therefore, this parameter and the depth of cut $\left(a_{\mathrm{p}}\right)$ were kept constant $\left(f\right.$ and $a_{\mathrm{p}}$ were $0.1 \mathrm{~mm}$ and $2 \mathrm{~mm}$, respectively), and only the cutting speed was varied so as to study its effect on the process. Yang and Liu (1999) claimed that when machining titanium alloys, the combination of the two factors - the small contact area and low thermal conductivity results in very high pressures and cutting temperatures; thus, the cutting speed for the titanium alloy must be low to avoid very short tool life. So, the cutting speed $\left(v_{c}\right)$ was varied from $40 \mathrm{~m} \mathrm{~min}^{-1}$ up to a maximum of $90 \mathrm{~m} \mathrm{~min}^{-1}$ for Ti6Al4V and a maximum of $60 \mathrm{~m} \mathrm{~min}^{-1}$ for Ti555.3. Higher speeds produced very high tool wear values for shorter cutting times. 

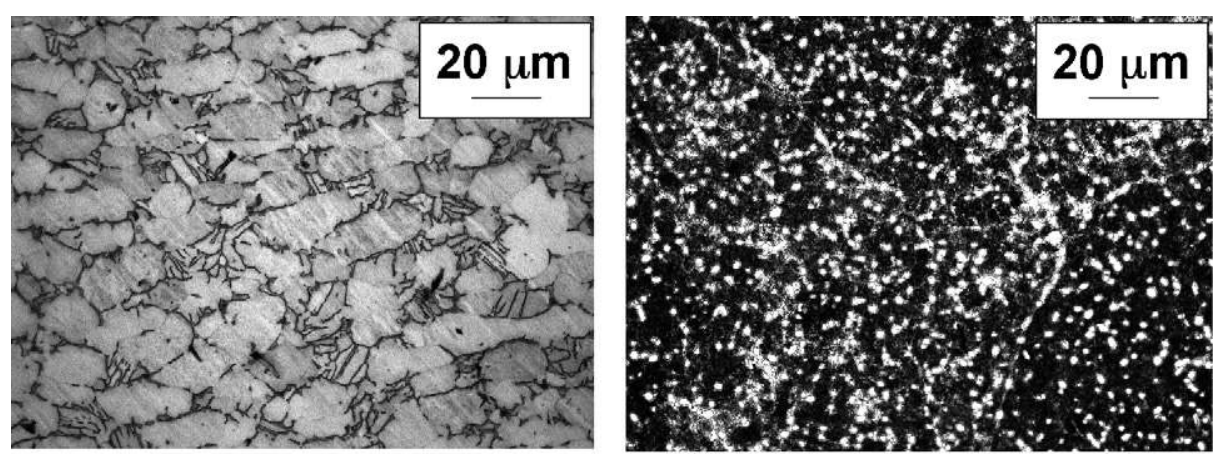

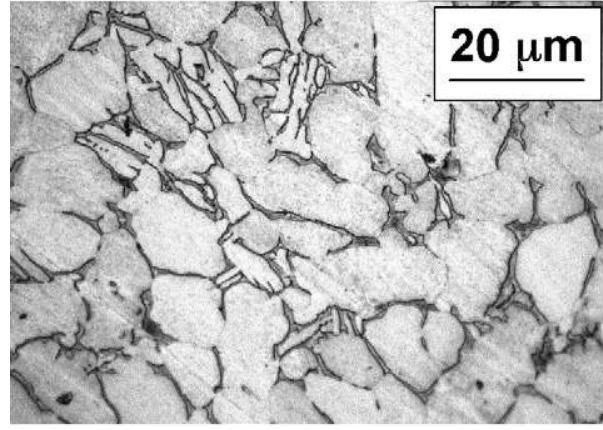

(a) Ti6Al4V

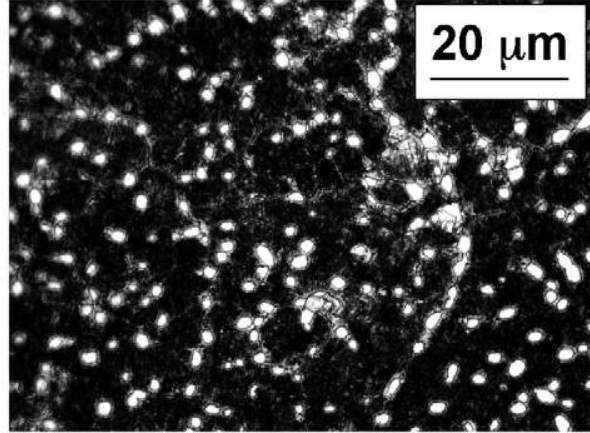

(b) Ti555.3

Fig. 2 - Microstructure of the titanium alloys.

The criteria of tool life is defined based on ISO3685, where the end of the tool life is reached when the average flank wear $\left(V_{B}\right)$ measures $0.3 \mathrm{~mm}$ for a $15 \mathrm{~min}$ cutting time.

Nabhani (2001) achieved successful results machining titanium alloys with ultra hard cutting tool materials like cubic boron nitride (CBN) and polycrystalline diamond (PCD). Similarly, Machado and Wallbank (1994) observed that tool life increases significantly by applying high-pressure coolant when machining. This study primarily focuses on the machinability of the near-beta titanium alloy using conventional cooling method and uncoated cemented carbide (grade K15 micrograin) tool.

The combination of tool holder (DCLNR $2525 \mathrm{M} 12$ ) and tool insert (CNMG 120408-23) provides the following tool geometrical features:

- Corner radius $\left(r_{\varepsilon}\right)=0.8 \mathrm{~mm}$.

- Cutting edge roundness $\left(r_{\beta}\right)=20 \pm 3 \mu \mathrm{m}$.

- Rake angle $\left(\gamma_{0}\right)=7^{\circ}$.

- Cutting edge angle $\left(\kappa_{\mathrm{r}}\right)=95^{\circ}$.

- Cutting edge inclination angle $\left(\lambda_{\mathrm{s}}\right)=-6^{\circ}$.

\section{Results}

In order to compare the machinability of Ti6Al4V and Ti555.3 alloys, the following were measured and analyzed after machining: (I) the specific cutting force and specific feed force, (II) tool wear, (III) chip morphology, and (IV) rake face and cutting edge after machining.

\subsection{Specific cutting force $\left(\mathrm{K}_{\mathrm{c}}\right)$ and specific feed force}

$\left(K_{k}\right)$

A piezoelectric sensor device was used to measure the component forces during the experiments. Fig. 4 shows the plots for the specific cutting force $\left(K_{c}\right)$ and specific feed force $\left(K_{k}\right)$, which depend on the material used and the cutting speed $\left(v_{c}\right)$.

The specific cutting force $\left(K_{c}\right)$ and the specific feed force $\left(K_{k}\right)$ values correlate well with the mechanical properties of the alloys, as lower values are obtained for the Ti6Al4V alloy whereas higher values are obtained for the Ti555.3 alloy. For instance, at a cutting speed $\left(v_{\mathrm{c}}\right)$ of $50 \mathrm{~m} \mathrm{~min}^{-1}$, the specific cutting force $\left(K_{\mathrm{C}}\right)$ varies from $2300 \mathrm{~N} \mathrm{~mm}^{-2}$ for Ti6Al4V to $2810 \mathrm{~N} \mathrm{~mm}^{-2}$ for Ti555.3. Similarly, the specific feed force $\left(K_{\mathrm{k}}\right)$ varies from $1270 \mathrm{~N} \mathrm{~mm}^{-2}$ for Ti6Al4V to $1950 \mathrm{~N} \mathrm{~mm}^{-2}$ for the Ti555.3 alloy. Thus, the difference between Ti6Al4V and the near-beta titanium alloy (Ti555.3) is more evident while considering the specific feed force $\left(K_{k}\right)$ than considering the specific cutting force $\left(K_{C}\right)$.
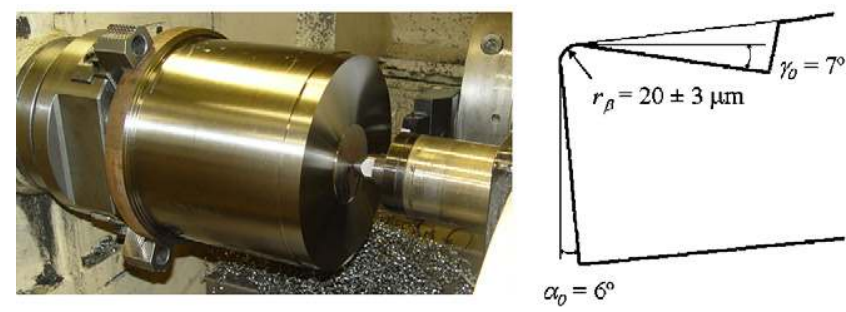

Fig. 3 - Experimental setup: Ti alloy bar and the tool insert geometry. 


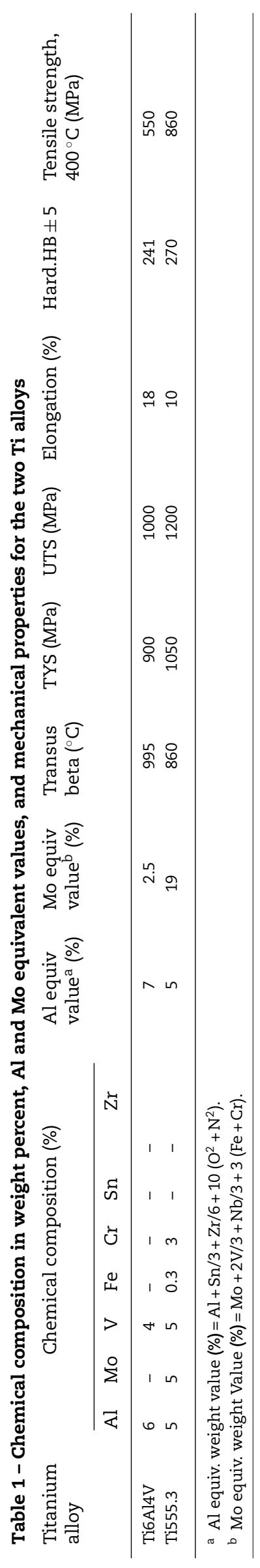

Arrazola et al. (2005) observed that the specific feed force $\left(K_{k}\right)$ indicates the friction and rubbing effects over the rake surface and thus shows the amount of heat generated at the tool-chip contact zone. Therefore, higher temperatures are expected in the near-beta titanium alloy compared with Ti6Al4V, which can promote diffusion wear and tearing of tool material particles.

For both Ti alloys, the specific cutting force $\left(K_{c}\right)$ and specific feed force $\left(K_{k}\right)$ decrease with increasing cutting speeds because of the decrease in the chip thickness and the lowering of the material flow stress due to softening of work material, the consequence of high temperature generation at the cutting interface.

\subsection{Tool wear analysis}

Dearnley and Grearson (1986) claimed that both flank wear and crater wear can occur on the insert tool during the machining of titanium alloys. However, in this study, only flank wear has been considered as a criterion for the end of the tool life, because it is always present and is the easiest to measure during machining (Fig. 5).

Ikuta et al. (2002) observed that the adhesion of chip material on the rake face occurred when machining both Ti6Al4V and the $\beta C$ Ti (Ti-3Al-8V-6Cr-4Mo-4Zr) alloys. The same phenomenon has been observed after machining both alloys. Min and Youzhen (1988) claimed that with the adhesion of the workpiece material to the tool rake face, diffusion is the most active wear mechanism for almost all tool materials when machining titanium alloys, as well as the tearing of tool material particles. This leads to crater wear and the weakening of the tool cutting edge (Fig. 5).

Fig. 6 shows the variation of tool flank wear with speed for a cutting time of $\mathrm{T}=15 \mathrm{~min}$ (close to the cutting time employed for machining operations in industry). A suitable maximum cutting speed $\left(v_{c, \max }\right)$ is determined for each alloy, which is the cutting speed beyond which a small increase in the cutting speed causes a rapid increase in tool wear.

It has been considered that the risk of rapid increase in tool wear occurs after approximately $\mathrm{VB}_{\max }=0.3 \mathrm{~mm}$ of wear. Additionally, in some instances notch wear is also observed (Fig. 5a). Considering these conditions, the maximum cutting speed $\left(v_{\mathrm{c}, \max }\right)$ for each alloy is quantified and presented as in Fig. 6, which are approximately 80 and $45 \mathrm{~m} \mathrm{~min}^{-1}$ for the Ti6Al4V and Ti.555.3 alloys, respectively. Kahles et al. (1985) used similar cutting speeds when machining Ti6Al4V.

However, a crater width (KB) close to 2 times the feed (f) value was observed after machining both Ti6Al4V and Ti555.3 for $15 \mathrm{~min}$ at the corresponding maximum cutting speed $\left(v_{c, \max }\right)$.

In essence, the classification of the alloys depending on the maximum cutting speed $\left(v_{\mathrm{c}, \max }\right)$ is representative of their machinability rate. It is also an indication of the total material that can be removed with one cutting edge of the tool. For instance, comparing the $v_{\mathrm{c}, \max }$ for both Ti6Al4V and Ti555.3 alloys, approximately $56 \%$ of material is expected to be removed for the latter alloy.

This value is in close association with the mechanical properties (hardness and hot tensile strength), chemical composition (Mo equivalent value), and the specific cutting 


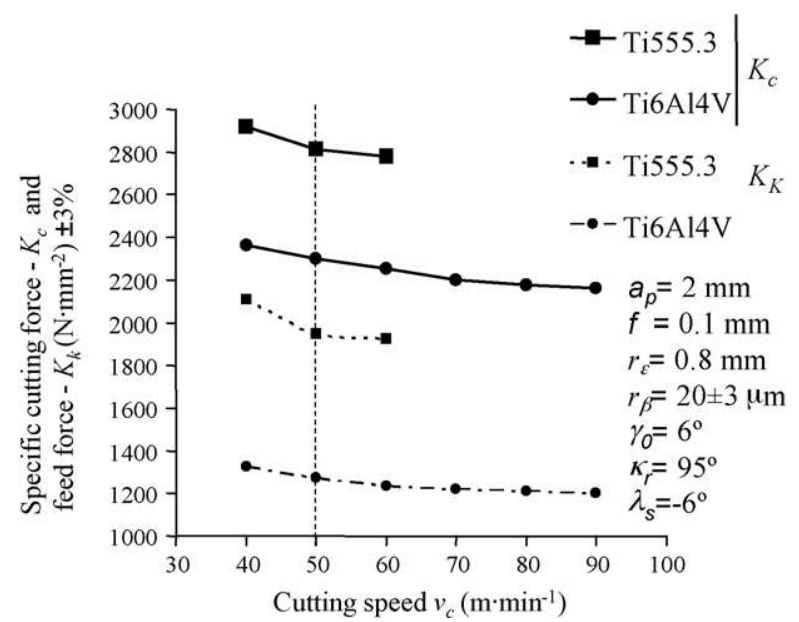

Fig. 4 - Specific cutting force $\left(K_{c}\right)$ and specific feed force $\left(K_{k}\right)$ dependence on the cutting speed $\left(v_{c}\right)$ and Ti alloy.

force $\left(K_{c}\right)$ and feed force $\left(K_{k}\right)$ for the various titanium alloys machined.

\subsection{Chip analysis}

Analyzing the chip formation for the two titanium alloys, some significant differences have been observed (Fig. 7). The

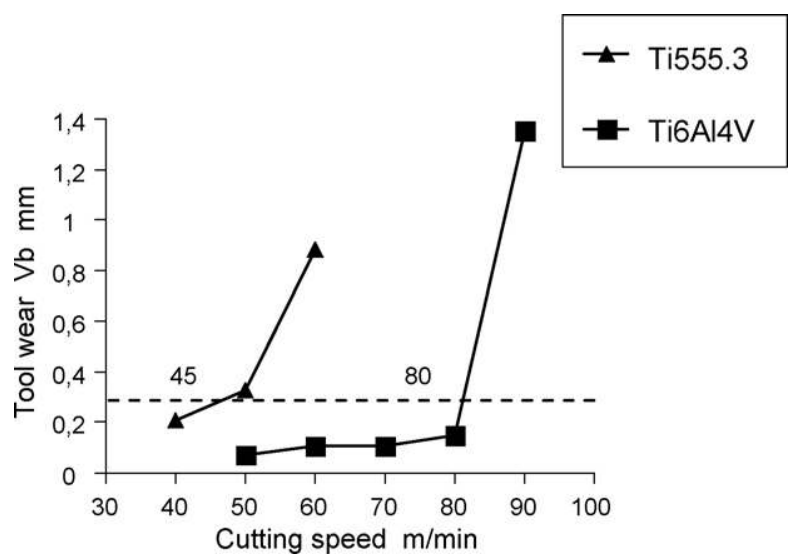

Fig. 6 - Flank wear area $\left(\mathrm{VB}_{\mathrm{Bmax}}\right)$ for $\mathrm{T}=15 \mathrm{~min}$ as a function of cutting speed $\left(v_{c}\right)$. (a) Ti6Al4V and (b) Ti555.3.

Ti6Al4V alloy yields "transitional chip" at the lower cutting speed condition, i.e., a nearly segmented chip without adiabatic shearing zones. The chip becomes more segmented at the highest cutting speed $\left(90 \mathrm{~m} \mathrm{~min}^{-1}\right)$ and shows distinct adiabatic shearing zones. On the contrary, the chips from the Ti555.3 alloy have narrow adiabatic shear bands at every cutting speed investigated. The full analysis of this phenomenon during the machining of Ti6Al4V alloy has been

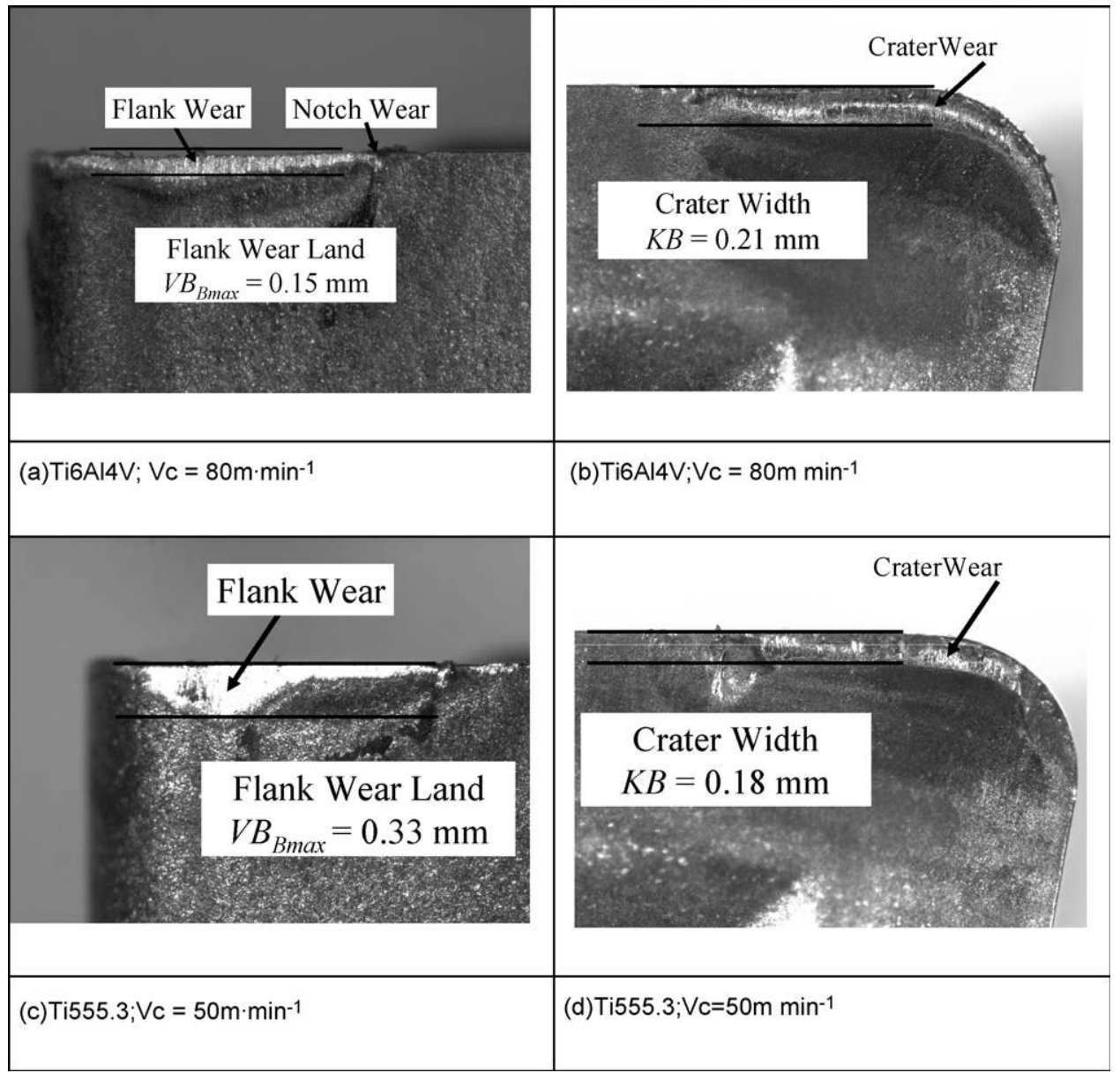

Fig. 5 - Flank and rake face wear patterns ( $T=15 \mathrm{~min})$. 
(a) Ti6Al4V

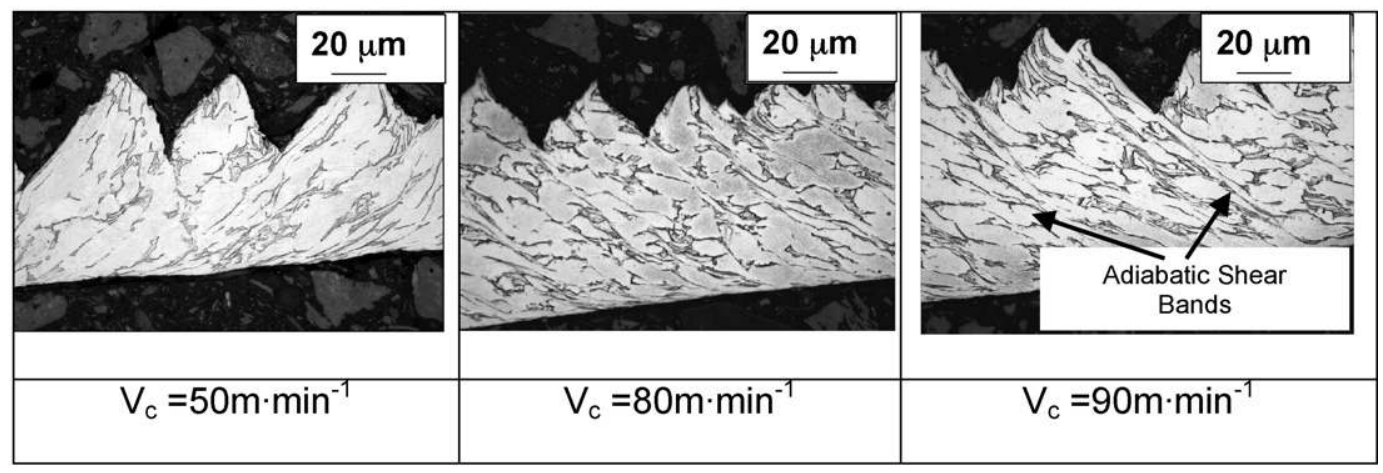

(b) Ti555.3

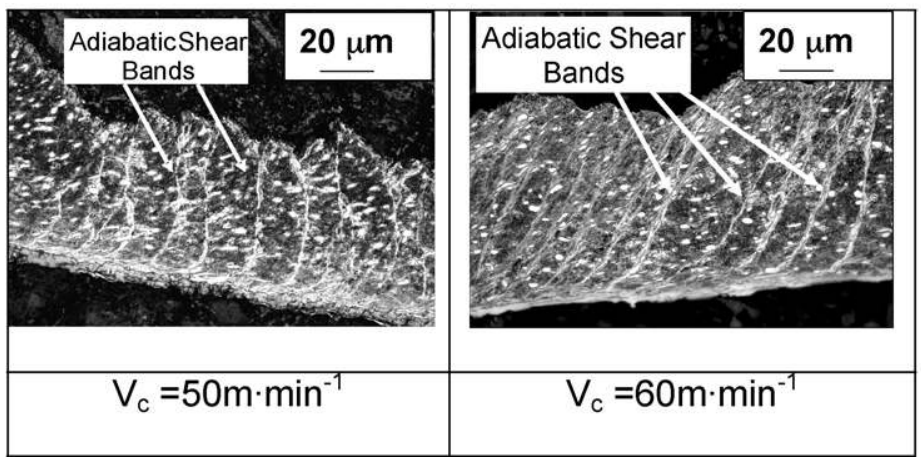

Fig. 7 - Chip morphology for the two Ti alloys for $T=15 \mathrm{~min}$.

reported by Komanduri (1982). The adiabatic shear bands observed in the Ti555.3 chips (Fig. 7) produced significant fluctuations in the component forces, resulting in a higher tool wear.

The frequency of formation of these adiabatic bands is much higher for Ti555.3 than for Ti6Al4V alloy. For example, at $90 \mathrm{~m} \mathrm{~min}^{-1}$, the Ti6Al4V alloy shows an adiabatic shear zone frequency of approximately $30-40 \mathrm{kHz}$, whereas the Ti555.3 alloy shows a frequency of $50-80 \mathrm{kHz}$ at $50 \mathrm{~m} \mathrm{~min}^{-1}$. The high frequency of formation of the adiabatic shear bands can explain why rapid tool wear and the damage to the cutting edges of inserts for the Ti555.3 alloy was observed.

\subsection{Rake surface and cutting edge analysis}

Fig. 8 shows images of the worn rake face of two inserts used during the machining of Ti6Al4V and Ti555.3 at 80 and $50 \mathrm{~m} \mathrm{~min}^{-1}$, respectively. A big amount of adhered material composed by titanium (light grey) and titanium carbide (black) was observed on each insert along the cutting edge.

EDAX analysis was carried out in order to identify the composition of the adhered material of each insert. Fig. 9a and $\mathrm{b}$ shows the composition of the black coloured regions in Fig. $8 a$ and $b$, respectively. The presence of titanium and carbon probes the existence of titanium carbide in the adhered (a)

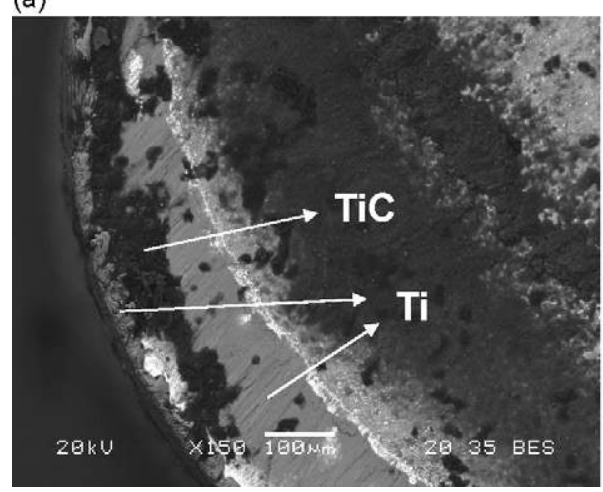

(b)

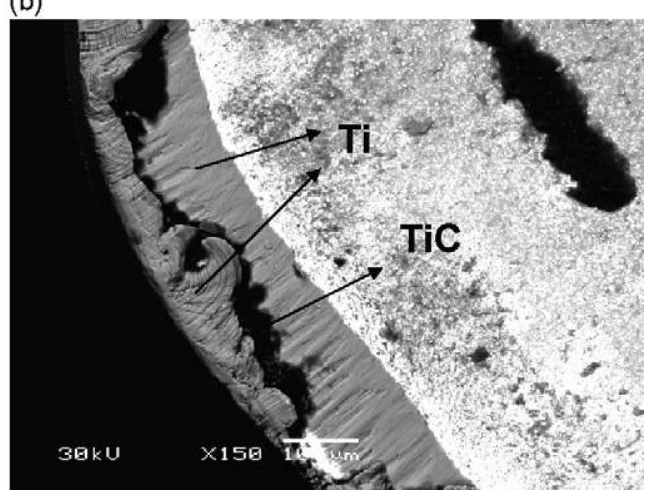

Fig. 8 - Adhered work material (B.U.L.) on the tool cutting edge for (a) Ti6Al4V at $80 \mathrm{~m} \cdot \mathrm{min}^{-1}$ and (b) Ti555.3 at $50 \mathrm{~m} \mathrm{~min}{ }^{-1}$ after $15 \mathrm{~min}$ of cutting time. 
(a) Full scale $=\mathbf{5 6} \mathrm{cps}$

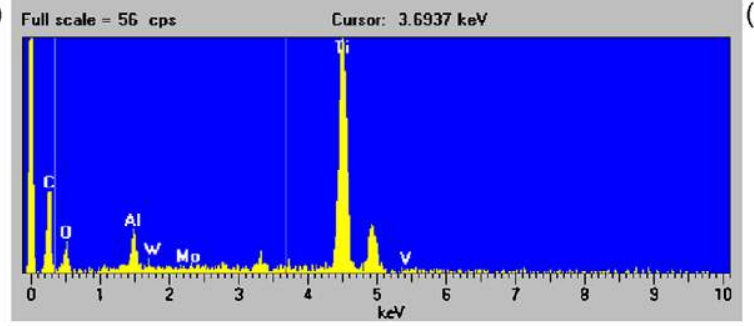

(b) Full stale $=57$ cps

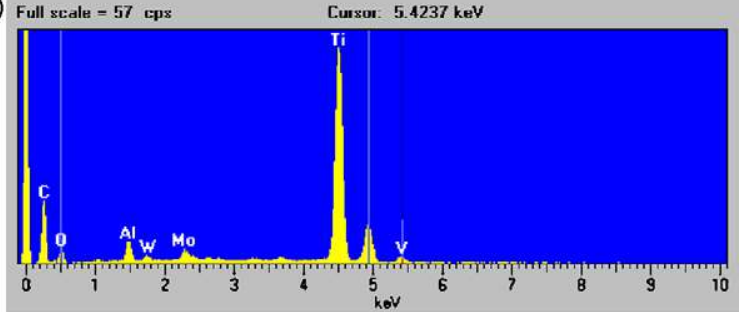

(c)

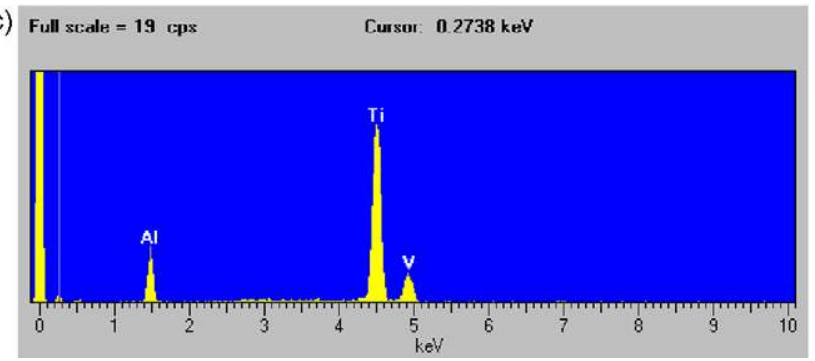

Fig. 9 - EDAX of the adhered material on the rake face of tool used to machine (a) Ti6Al4V at $80 \mathrm{~m} \cdot \mathrm{min}^{-1}$ (black region along the cutting edge in Fig. 8a); (b) Ti555.3 at $50 \mathrm{~m} \mathrm{~min}^{-1}$ (black region along the cutting edge in Fig. 8b; and (c) light grey regions (along the cutting edge) in Fig. 8.
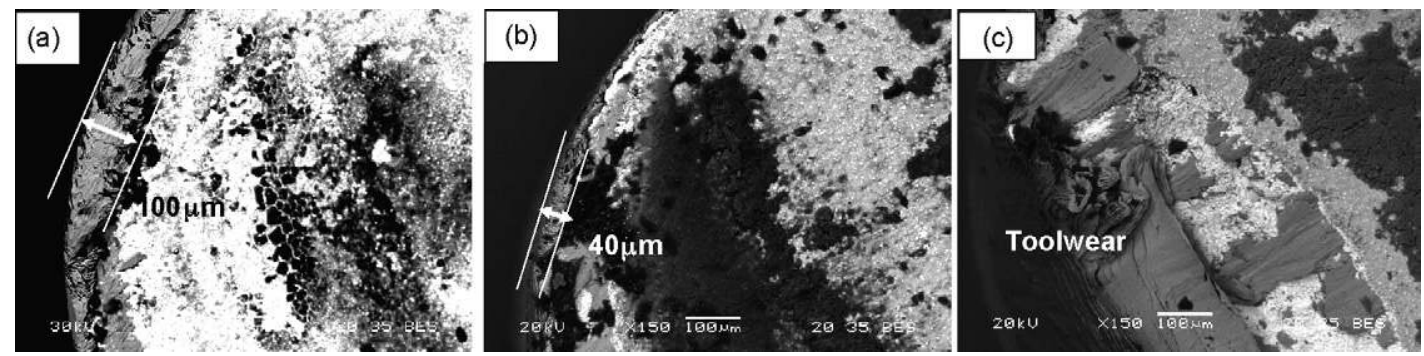

Fig. 10 - An evolution of the build up layer in the inserts at (a) $V_{c}=50$, (b) $V_{c}=80$, and (c) $V_{c}=90 \mathrm{~m} \mathrm{~min}^{-1}$ for Ti6Al4V (cutting edge).

material. Hartung and Kramer (1982) and Ikuta et al. (2002) observed the formation of this compound in the machining of the Ti6Al4V alloy. The presence of carbon in the adhered material indicates that the phenomenon of diffusion of carbon from the inserts into the work material has taken place at the tool-chip interface. Besides Ti and C, EDAX plots show the presence of different alloying elements of the analyzed titanium alloys: aluminium, vanadium and molybdenum. On the other hand, Fig. 9c shows the composition of the light grey coloured regions in Fig. 8. In this case the adhered material contains only the different alloying elements (titanium, vanadium and aluminium), with no evidence of carbon.

Hartung and Kramer, 1982 observed the presence of a stable built-up layer after machining the Ti6Al4V alloy at low cutting speeds and suggested that tool wear is considerably reduced when this layer appears as it prevents relative sliding at the tool-chip interface and limits the diffusion rate of the tool constituents. At higher cutting speed conditions, this built up layer disappears and rapid tool wear begins. This fact has been verified in this study by the observation of the reduction of the titanium protective layer when the cutting speed was increased (Fig. 10a and b). At a cutting speed of $90 \mathrm{~m} \mathrm{~min}^{-1}$, the protective layer was completely removed (Fig. 10c) and the tool wear increased sharply (Fig. 6).

\section{Conclusions}

1. The machinability rate of Ti6Al4V is higher than that of Ti555.3. Comparing the maximum cutting speed of the two alloys, it can be deduced that the machinability of the latter could be approximately $56 \%$ of the former.

2. There is a close relationship between the machinability rate and the mechanical properties of the work material (hardness and hot tensile strength), chemical composition (Mo equivalent value) as well as the chip morphology, specific cutting force $\left(K_{C}\right)$, and specific feed force $\left(K_{k}\right)$.

3. Higher $K_{k}$ and $K_{c}$ values are observed for Ti555.3 than for Ti6Al4V in all the cutting speed conditions investigated. The difference between the $K_{\mathrm{k}}$ values $(800 \mathrm{MPa})$ is significantly higher than the respective $K_{\mathrm{c}}$ values(400 MPa). 
4. The presence of adiabatic shear bands in the chips of Ti555.3 alloy could increase the fluctuations in the mechanical and thermal loads over the tool rake face leading to an accelerated tool wear by diffusion wear mechanism.

5. SEM observations of the worn tools indicate the presence of titanium carbide for the tools employed for machining Ti555.3 and Ti6Al4V. The presence of carbon in the adhered material indicates that the phenomenon of diffusion of carbon from the inserts into the work material has taken place at the tool-chip interface.

6. The formation of a protective layer of adhered material has been observed when machining Ti6Al4V alloy. The size of this layer decreases with increasing speed. As soon as this layer is removed, tool wear increases brusquely.

As a future prospect, the improvement of the machinability of this alloy could be achieved through the use of different advanced tool materials and a significant modification to the process setup right from the forging process to heat treatments in particular. However, as Delfosse (2005) observed, the choice of the treatment after forging could be determined by the influence of the alloys structure (phases alpha-GB and alpha-WGB) on the fatigue properties.

\section{Acknowledgments}

The authors hereby thank the Basque Government for the financial support given to the project TAF (IE05-148). The authors also thank the companies Timet (UgineFrance), Sandvik (France), and the Association Française du Titane for the technical and material support given to this study.

\section{REFEREN C ES}

Arrazola, P.-J., Meslin, F., Marya, S., 2005. Serrated chip prediction in numerical cutting models. In: Proceedings of the CIRP Congress 8 WMMO, pp. 115-122.

Boyer, R.R., Briggs, R.D., 2004. The use of beta titanium alloys in the aerospace industry. Journal of Materials Engineering and Performance 56, 681-685.

Dearnley, P.-A., Grearson, A.-N., 1986. Evaluation of Principal Wear Mechanisms of Cemented Carbides and Ceramics Used for a Machining Titanium Alloy IMI 318. Materials Science and Technology 2, 47-58.

Delfosse, J., 2005, Forgeage beta du Ti17 Propriété en fatigue. PhD. Thesis, Ecole Centrale Paris, France.

Fanning, J.-C., 2005. Properties of TIMETAL 555 (Ti-5.5Al-5Mo-5V-3Cr). Journal of Materials Engineering and Performance 14, 788-791.

Hartung, P.-D., Kramer, B.-M., 1982. Tool wear in Titanium machining. Annals of CIRP 32 (1), 75-80.

Ikuta, A., Shinozaki, K., Masuda, H., Tamame, Y., Kuroki, H., Fukaya, Y., 2002. Consideration of the adhesion mechanism of Ti alloys using cemented carbide during the cutting process. Journal of Materials. Processing 127 (September (30)), 251-255.

Kahles, J.-F., Field, M., Eylon, D., Fores, F.-H., April 1985. Machining of titanium alloys. Journal of Metals, 7-35.

Komanduri, R., 1982. Some clarifications on the mechanics of the chip formation when machining titanium alloys. Wear 76 (February (1)), 12-34.

Machado, A.-R., Wallbank, J., 1994. The effects of a high pressure coolant jet on machining. Journal of Engineering Manufacture 208 (B1), 29-38.

Min, W., Youzhen, Z., 1988. Diffusion wear in milling titanium alloys. Materials and Science Technology 4 (January (6)), 548-553.

Nabhani, F., 2001. Wear mechanism of ultra-hard cutting tool materials. Journal of Materials Processing Technology 115 (September (3)), 402-412.

Yang, X., Liu, R.-C., 1999. Machining titanium and its alloys. Machining Science and Technology 3 (1), 107-139. 